\title{
Support System for Operation Status Awareness and Troubleshooting of UHVDC Transmission System
}

\author{
Jinjun $\mathrm{Lu}^{1,2}$, Xin Shan ${ }^{1,2}$, Yi Wang ${ }^{1,2}$ and $\mathrm{Xi} \mathrm{Xu^{1,2 }}$ \\ ${ }^{1}$ NARI Technology Co. Ltd., Nanjing 211106, China \\ ${ }^{2}$ State Key Laboratory of Smart Grid Protection and Control, Nanjing 211106, China
}

\begin{abstract}
The transmission capacity of ultra-high voltage direct current (UHVDC) transmission system is huge. Once a fault occurs, it will bring tremendous impact on the operation of the power grid, bring about a number of problems such as power flow overload, insufficient reserve, and frequency drop, and induce chain failure. Therefore, it is necessary to adopt a comprehensive Precautions. This article describes the specific ideas and implementation methods of solving problems from the overall solutions to the handling of UHVDC faults, the risk assessment and prevention in advance, the real-time monitoring of events, and the assistance in emergency recovery afterwards. The method mentioned above has been operated in some regional and provincial power companies for demo purpose, and has played an important role in the handling of DC blocking events many times.
\end{abstract}

Keywords- Ultra-high voltage direct current (UHVDC); Risk assessment; Assistance decision; Preventive control; Real-time monitoring

\section{INTRODUCTION}

China's energy resources and load are adversely distributed, a large number of available energy resources are mainly distributed in southwest (hydropower), northwest (hydropower, wind power, photovoltaic, coal power), northeast (wind power) and North China (thermal power, wind power), the main load center is concentrated in the southeast coastal areas,, centers of energy resources and load centers are thousands of miles apart. In the meantime, with the implementation of the "Air Pollution Prevention and Control Plan", vigorously developing clean energy and controlling the development of coal power has become the established direction for a considerable period of time now and in the future ${ }^{[1]}$. The UHVDC transmission system has the characteristics of long distance and large transmission capacity. It has become an inevitable choice to concentrate the large-scale clean energy in southwest, northwest and north China to the east load center by UHVDC. The construction and operation of a large number of UHVDC transmission systems have greatly enhanced the large-scale optimal allocation of resources and the trans-regional clean energy transmission capacity in China's power grid, but also brought great challenges to the safe operation of the power grid: (1) UHVDC transmission system across multiple provinces and autonomous regions, up to thousands of kilometers, and along which the terrain and weather conditions are so complex that the possibility of failure increased significantly ${ }^{[2]}$; (2) the UHVDC transmission capacity is so big that once a DC blocking fault or continuous commutation failure occurs, the power balance, voltage and frequency stability of the transmission power grid will be greatly affected ${ }^{[3]}$; (3) The UHV DC drop relatively concentrated (such as Guangdong, East China and other provinces), the interaction between $\mathrm{AC}$ and $\mathrm{DC}$ and multi-DC systems is complex and can easily lead to the occurrence of chain failure accidents ${ }^{[4]}$. The treatment of the problems mentioned above involves planning, mode, scheduling, monitoring and other professional aspects, which must be considered as a whole.

At present, the research on UHVDC fault mostly focuses on the mechanism of chain failure and the configuration of security control strategy. The existing fault diagnosis techniques are all aimed at the conventional AC power grid. The research on the on-line diagnosis of UHVDC fault is inadequate. At the dispatch end, no integrity solution has yet been formed on the risk of UHVDC faults and their treatment technologies. Targeted research must be carried out.

\section{ARCHITECTURE}

The coupling characteristics of AC and DC power grid, power supply and load center, upper and lower levels of China's power grid determine the UHVDC transmission system fault disposal must adopt comprehensive prevention and control measures, considering from many different dimensions such as time, space, object and control. In the time dimension, we need to start with the risk assessment and correction control service decision beforehand, the on-line monitoring and comprehensive alarm in the event, and the quick recovery auxiliary decision-making afterwards; In the space dimension, it is necessary to coordinate the various resources of power supply and load center, dispatching agencies at the upper and lower levels, main station and sub-station, and implement collaborative analysis and disposal. In the control and object dimension, it is necessary to integrate different applications at the master station, comprehensively implement various types of active and reactive resources with different characteristics in the power grid for quick decision making and control execution, and restore the post-fault power grid to a stable operation state with a high safety margin as much as possible.

While realizing, it is necessary to make full use of the advantages of "horizontal integration and longitudinal penetration" of the existing intelligent power grid dispatching control system, comprehensively use grid operation steady state, dynamic and transient data to judge the operation status of power grid online and share it between power supply and load center, dispatching agencies at the upper and lower levels. 
Integrate electrical safety assessment, the AGC and AVC, realtime scheduling plan, integrated intelligent analysis and warning to make an application function, achieve rapid analysis and response decision, and by means of batch group control technology etc. to achieve obvious rapid execution, as far as possible to restore power grid operation state.

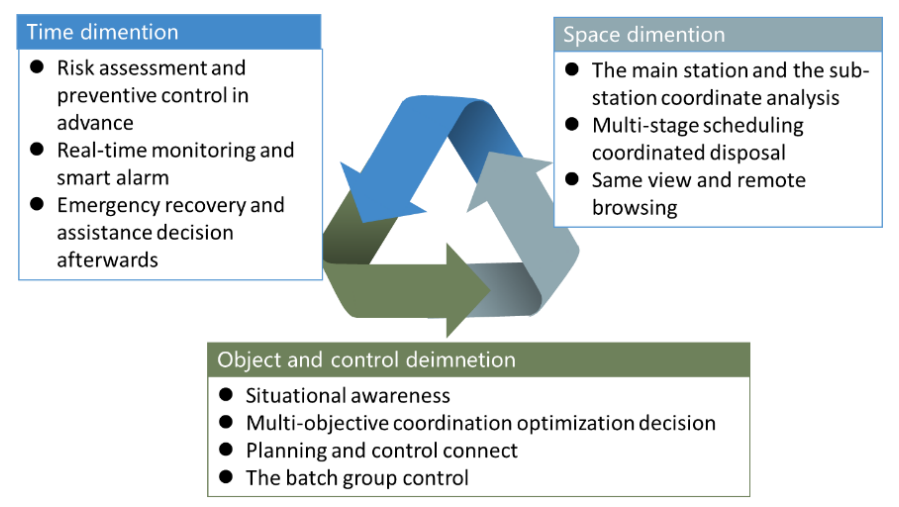

FIGURE I. THREE DIMENSIONS OF UHVDC FAULT TREATMENT

\section{DC SYSTEM RISK ASSESSMENT AND AUXILIARY DECISION}

\section{A. Risk Assessment}

The reason for the commutation failure of DC system and continuous commutation failure which lead to DC block mainly includes: (1) serious waveform distortion caused by the normal operation of AC system, such as excitation inrush current of large capacity transformers; (2) failure of AC system can lead to the failure of dynamic reactive power support in $\mathrm{AC}$ substation of the converter, the voltage drop amplitude is larger, which induced commutation failure. (3) the fault of DC transmission line, converter or DC control device, causing DC protective action; (4) in the dense area of DC drop point, the other converter station blocking failure, grid current and voltage changes significantly, resulting in local converter station failure; (5) The above factors stack. The DC risk assessment requires pre-evaluation and analysis of the above potential DC operation faults.

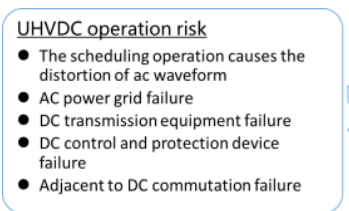

$A C$ and $D C$ system operation risk

- Power current upheaval leads to $A C$ protection mis-action

- DC convert failure leads to adjacent DC fault

- Insufficient reserve leads to

continuous reduction of frequency

- Voltage/frequency change leads to new energy units off

- Voltage/frequency change leads to chaining trip of units

\section{FIGURE II. RISK ASSESSMENT OF DC SYSTEM}

In addition to the above-mentioned risk of DC system failure, it is also necessary to assess the risk of a cascading failure or systematic disaster after a DC system failure, and to establish an impact safety assessment system of UHV DC system faults on the power supply and load center of AC system. Including: (1) after the failure of the DC system, the change of the distribution of power flow in the power grid, the possibility of wrong actions of protection and security automatic equipment; (2) after the failure of the DC system, the $\mathrm{AC}$ voltage level of the DC system in the adjacent area will change, and the possibility of Commutation failure; (3) after the failure of the DC system, the power grid frequency drop situation of the load center of the grid, whether the frequency is lower than the threshold for a long time or collapse, the grid frequency suddenly lifting or dropping cause cascading trip problem of the units etc. (4) impact assessment of the power grid voltage and frequency changes to the large-scale wind power and other new energy.

The implementation of the above functions requires the detailed configuration information of equipment and systems such as protection, safety and stability control devices, etc., as well as the upgrading of the online application functions such as static safety analysis, DSA, TSA, AVC and so on. The accurate AGC and AVC control models need to be established. The dynamic response model of station filter, AVC, SVG, pumping and other equipment and devices need to be established. The grid operating state after the DC system failure need precise assessment.

\section{B. Prevention and Control Assistance Decision}

Prevention and control of auxiliary strategies need to consider the prevention of DC blocking, and in case of failure considering the system security control measures, reserve capacity recommendations, the optimal distribution of power flow, DC line load shedding, scheduling adjustment, increase dynamic reactive power reserve, and through Visual display means for dispatchers to choose, verify and execute. As the optimal operation mode of the power grid involves both power supply and load center, dispatching agencies at the upper and lower levels, the auxiliary decision-making information will be sent to all levels of dispatching at the same time, and the higher-level dispatching agencies coordinate all their actions.

When it comes to realization, various methods such as sensitivity analysis, equal matching method and multi-objective optimization algorithm can be used synthetically to ensure the stability of calculation and good convergence.

\section{DC Fault Online Diagnosis}

At present, the online fault diagnosis and integrated intelligent alarm technology for the AC system is relatively mature. It has been widely used in the control centers at provincial level and above in the country, with a correct rate of over $99 \%$. But for the UHVDC transmission system, because there are too many reasons for the formation of faults and the collection range and information of the master station are not sufficient, the success rate of fault diagnosis is relatively low, and the fault information given is relatively limited, which is not enough to support the scheduling Real-time processing.

In order to meet the need of on-line diagnosis of DC faults, it is necessary to start from both the master station and substation, make full use of the centralized information of the whole network at the master station and the rich information and comprehensive advantages of the converter station, and establish the Online Diagnosis Mechanism of DC Fault in coordinated master station and sub-station. Specifically, at the converter station side, it is possible to give DC fault type and characteristic information according to the DC fault protection and the fault waveform collected by the control system, fault 
alarm signal, protection action signal, etc., and finally form a failure briefing to the master station. At the master station, in order to improve the correct rate, we can comprehensively analyze the SCADA data collected by the converter station, the remote signals and telemetering signals data of the station near the converter station together with the fault briefing data sent from the converter station.

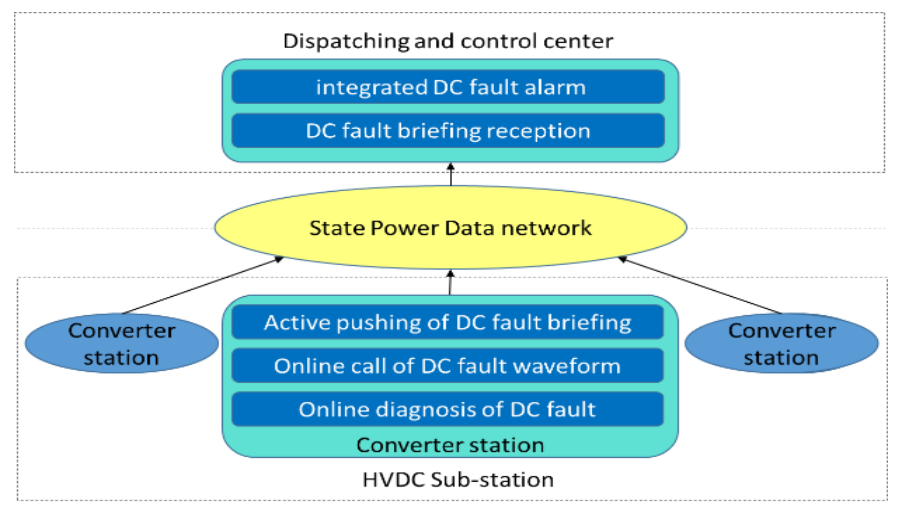

\section{FIGURE III. COORDINATED FAILURE ANALYSIS OF MASTER STATION AND SUB-STATION}

At the same time, the master station can make a comprehensive reasoning according to the timing relationship of all kinds of different signals during the accident process, the connection of the power grid topology and the causal chain of accidents to form an event chain of accident evolution and display it to the dispatcher through visualization so that the dispatcher can make emergency accident handling. Fault briefings, event chains, and key equipment and section information during the evolution of the accident can also be shared between the upper and lower dispatchers, dispatchers of power supply and load center through the wide area service bus in real time, facilitating collaborative disposition of the multilevel dispatcher for DC fault.

For UHVDC fault or AC / DC chain failure, through the disturbance case management technology it can also automatically save fault information, accident briefings, alarm information, analysis of various safety assessment software, control decisions and command execution of Various types of real-time control software before and after the accident. As a result, It provides the basis for detailed analysis afterwards and further optimization of power grid operation.

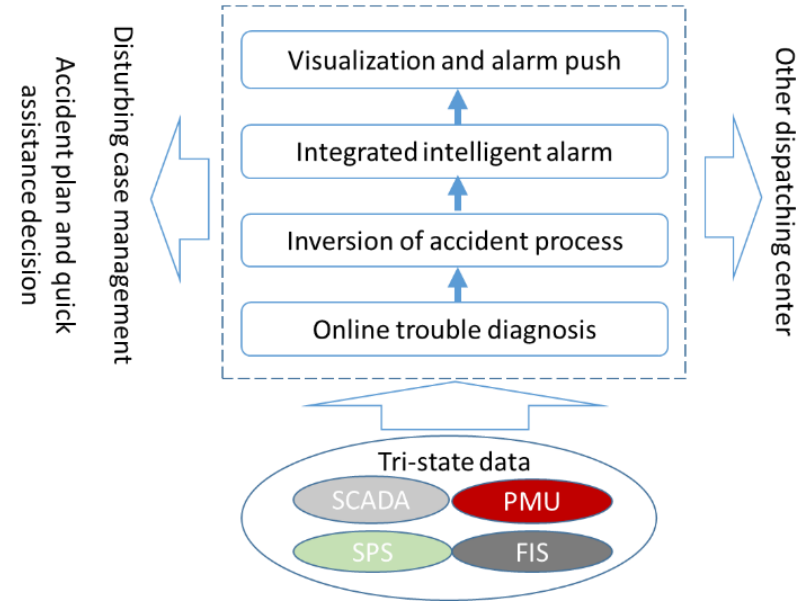

FIGURE IV ONLINE UHNDC FAULT DIAGNOSIS

\section{DC Fault Fast Recovery Auxiliary Decision Processing}

After the UHVDC fault, the protection and safety control devices will operate according to the pre-set sequence to keep the main network as stable as possible. However, due to the huge transmission capacity of the UHVDC system and economy of the power grid, the balance state is relatively fragile after the fault, usually there will be insufficient capacity of the system back-up, local power flow overload, district power grid near converter station meets structural weakness of the power grid or lack of dynamic reactive power support, if a major disturbance in the grid occurred again, it is likely to induce a series of cascading failure incidents, resulting in a large power outage.

Therefore, in order to ensure the safety of the power grid, it is necessary to realize "quick decision-making and rapid control" according to the latest grid operation state after the UHVDC fault occurs. For the frequency drop problem after the fault, It can be solved by means of emergency power support of multi-dc system, operation state conversion of pumping unit (From pumping to power generation), and rapid increase of unit output.

For the problem of insufficient backup capacity of the power grid, it can be solved by emergency start of standby units, real-time planning curve adjustment and emergency standby support of adjacent power grids. For local power flow overload, it can be solved through adjust the output of the unit, adjust the tap of the transformer, adjust the reactive power of the unit, switch of the capacitor and so on. In addition, other measures such as load limitation can also be used to solve the problem of grid power flow overload and frequency off-limit when necessary. When multiple problems occur simultaneously, a multi-objective optimization method can be adopted, which combines with the operation limits of the power grid, the adjustable range of the equipment, etc. to form a sequential optimization control strategy and deliver the execution. 


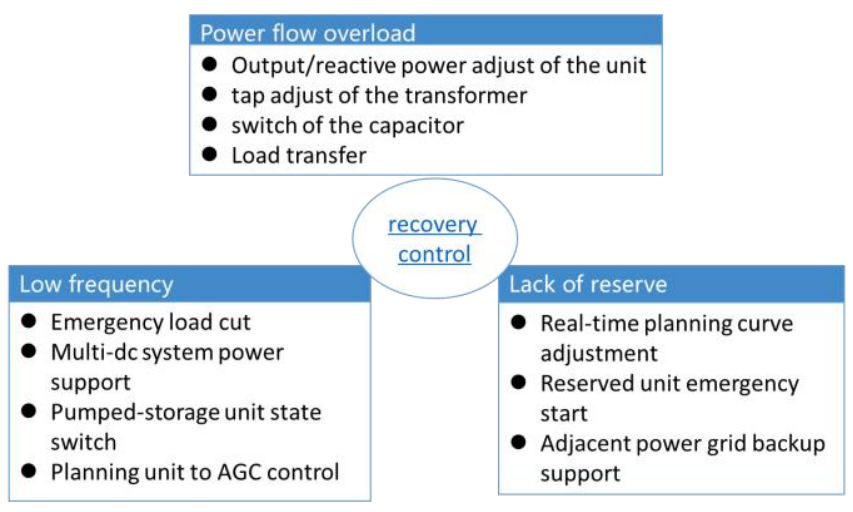

\section{FIGURE V QUICK RECOVERY CONTROL MEASURES}

For the control command execution, due to a large number of switching operations and unit operation status adjustment, conventional remote control, remote control mode action time is too long, it is difficult to meet the grid control and regulation needs after the DC fault. In response to the above problems, the system developed practical control software such as one-key AGC state switching and batch load sequence control of the entire network, shortening the control time more than 10 times, and better meeting the real-time scheduling requirements after DC fault.

In the control system, coordinated load control between principal and municipal control centers can be adopted. Provincial control center determines the total need to cut the load according to the grid operating status, and distributes the total need to the relevant municipal control center, it's up to the municipal control center to execute the load-shedding operation. The benefits of the solution are the responsibilities of provincial and municipal control centers are clear, compared to provincial control center, municipal control center has relative more detailed load mode, and is easier to complete loadshedding tasks through multiple rounds of approach to avoid over-cutting.

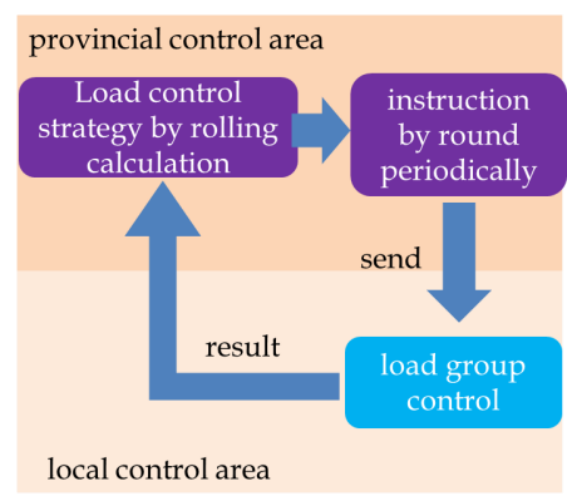

FIGURE VI COORDINATED LOAD CONTROL BETWEEN PRINCIPAL AND MUNICIPAL CONTROL CENTERS

\section{ENGINEERING APPLICATIONS}

The technology of UHVDC fault treatment such as UHVDC risk assessment, on-line fault diagnosis, batch load group control and AGC unit "one-key" switching introduced in this paper has been applied in many provincial and above control centers. The operation has played an important role.

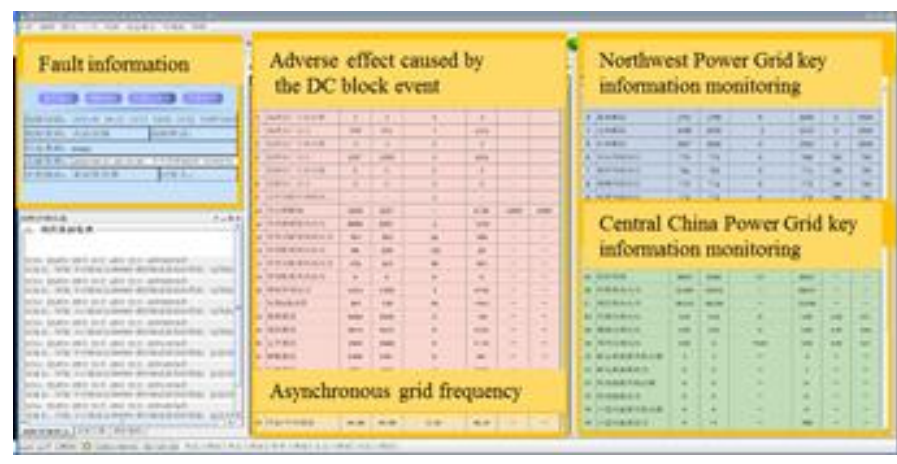

FIGURE VII UHVDC FAULT TREATMENT IN TIAN ZHONG

The figure above shows the concentrated display of critical information such as overload, spare capacity, frequency-limited, cutting machine, and load-shedding at all levels of control center under the condition of UHVDC fault in Tian Zhong. According to the graphic information, the power supply and load control center and the state control center's control personnel can quickly grasp the occurrence and evolution of the DC fault and its impact on the sending and receiving AC network, so as to facilitate the coordination of the dispatching personnel on both sides quickly to mitigate the influence of the fault, to prevent the scope of the accident expanded.

\section{SUMMARY}

This paper provides a systematic solution for the dispatcher to monitor the operating status of the UHVDC system in real time, and to analyze and deal with the DC fault quickly. The method has been tested in practice. However, accurate Simulation of the dynamic full response process of the grid after the UHVDC fault and multi-objective control strategy optimization needs further study.

\section{ACKNOWLEDGMENT}

This research was financially supported by Science and Technology Project of State Grid Corporation China "Research on Key Technology of UHVDC Fault Analysis and Codisposal".

\section{REFERENCES}

[1] National Enegy Administration. The electric power development planning "in 13th Five-Year" (2016-2020)

[2] LI Xinnian, YI Jun, LI Baiqing, SUN Huadong, LEI Xiao, ZENG Nanchao. Simulation Analysis and Operation Statistics of Commutation Failure in HVDC Transmission System. Power System Technology[J], 2012, 36(6):266-271.

[3] LI Zhaowei, ZHAI Haibao, LIU Fusuo, HUANG Zhilong, CUI Xiaodan, LI Wei. DC access capability study for multi-infeed HVDC power transmission system. Power System Protection and Control[J], 2016, 44(8):142-148.

[4] QIN Qin, GUO Qiang, ZHOU Qinyong,etal. Thesecurityand stability of power girds in 13th Five Year Planning and countermeasures[J]. Electirc Power, 2015, 48(1):25-32. 